\title{
An Evaluation of the Chemical Composition of Soft Drinks in Nigeria: A Principal Component Analysis Approach
}

\author{
Samuel Olorunfemi Adams*, Rafiu Olayinka Akano, Rauf Ibrahim Rauf \\ Department of Statistics, University of Abuja, Abuja, Nigeria
}

Corresponding Author Email: samuel.adams@uniabuja.edu.ng

https://doi.org/10.18280/ama_a.571-403

Received: 27 August 2020

Accepted: 12 October 2020

\author{
Keywords: \\ Carbonated water, colouring, fructose, main \\ concentration, soft drink, stabiliser, sucrose
}

\begin{abstract}
This study aims to determine the relationship between the chemical compositions of twenty-five (25) soft drinks sold in Nigeria. Sample concentration of twenty-five (25) soft drinks used in the study was collected from the National Agency for Food and Drug Administration and Control (NAFDAC). Principal Component Analysis (PCA) was employed to explain the relationship between the chemical compositions and determine the soft drinks' chemical composition distribution. The result has shown that all except acidity and antioxidant has a significantly strong positive relationship among the chemical structures. PCA suggested retaining three components that explained about 82.465 per cent of the data set's total variability. It was observed that carbonated water, fructose, sucrose, main concentration, stabiliser, E412, colouring and gelatin were the major compositions of the soft drinks in Nigeria, Base on the findings in this study, it is recommendations that; Consumers who are allergic to sugar or diabetic should avoid taking any of the soft drinks with high sugar concentration. Soft drinks companies producing drinks with high sugar content should consider their customers who are diabetic and allergic to high sugar levels.
\end{abstract}

\section{INTRODUCTION}

Soft drinks' is used to define beverages with remarkable alcoholic or hot beverages, this includes an enormous array of products ranging in arrangement from mineral waters, sports drinks, diet formulations, colas, mixers, and tonics to fruit juices, and few soft drinks are sparkling (carbonated), whereas others are still. Some are produced with a designated shelf-life higher than a year, whereas others are sold for immediate consumption (freshly squeezed juices) [1]. As a result of this change in composition and endorsement, soft drinks' microbiology also shows appreciable changes. Some soft drinks form an aggressive environment, or so deficient in nutrients that the microflora is nearly nonexistent, and spoilage is rare. New soft drinks, such as fruit juices of a higher $\mathrm{pH}$ form an environment ideal for the rapid proliferation of yeasts, moulds, and bacteria, were produced in large quantities [2].

Soft drinks may make a valuable addition to fluid intake and have become, to some extent, determined as part of the daily diet, particularly of young children and adolescents. The nutritional value of some readily available soft drinks include; Squashes, crushes, cordials, and carbonated beverages are, however, of little nutritional value (apart from their energy content) as their main ingredients are water and sugar. These soft drinks can be a useful vitamin $\mathrm{C}$ source, although they are unlikely to contain a substantial amount unless the vitamin is included. Soft drinks do not contain fat or fibre but may contain nutritionally insignificant protein traces [3].

The energy theme of soft drinks varies greatly and is derived wholly from the sweetening agents, principally sugars. Soft drinks sweetened with a combination of sugar and intense sweeteners are less caloric than drinks sweetened entirely with sugar, and beverages labelled as low-calorie are required by
United Kingdom law to contribute a maximum of $22 \mathrm{~kJ}$ (5 $\mathrm{kcal})$ per $100 \mathrm{ml}$. [4]. The added sugar theme of soft drinks ranges from 6 to $10 \%$ and is usually made up of glucose and fructose, with small sucrose and perhaps maltose. The sugar theme of soft beverages is regulated by the United Kingdom 1964 Soft Drinks Regulations (amended 1969, 1970, and 1976). The beneficial assessment of a soft drink as taken depends on the watering factor, which must now be stated on the label of all dilutable drinks. Soft drinks are a significant market for energy sweeteners, mostly in the United Kingdom. Unlike other countries, they can be used together with nutritive sweeteners and are therefore restricted to dietetic beverages. There are scientific reasons and objectives for considering the need for intense sweeteners in soft drinks. Not one sweetener is grandly suited to meet all the soft drinks conditions, and another's vigour can offset one sweetener's weakness. The enhancement of soft drinks with artificial sweeteners reduces the energy content and encourages fluid consumption without decreasing the diet's nutrient density. The more progressive use of artificial sweeteners, the more the acceptability of daily intake levels, and the increased number of sweeteners available have resulted in a wide range of low-calorie beverages sufficient to many buyers. Customers have been directed to ensure that they take a blend of sweeteners to avoid vast intakes of any one type [5]. Soft drinks are widely consumed in Nigeria, and it is generally believed that they contain large amounts of sugars, calories and many other ingredients. However, there is no local study to define these drinks' composition and classify them using statistical tools. This information is essential in giving dietary advice, especially to those on special diets. Soft drinks exist in various compositions and brands and are marketed by different brewery industries $[6,7]$. These drinks are readily devoured 
daily, especially when undergoing worrisome activities like hard work and sport [8]. With the relatively economical prices, they are highly consumed during leisure and relaxation outings and serve the general public on occasions such as traditional marriages, weddings, funerals, etc. [9]. The tremendous volume consumption rate of soft drink is attributed to the characteristic taste and flavour and their thirst extinction potential [10]. These attributes are defined by the Constituents present such as sugar responsible for its sweetness, carbonated water that is water compressed with carbon dioxide makes it the best thirst quencher and flavouring agents to add flavour to the drinks [11]. In addition to taste pleasure, soft drinks contain other ingredients such as vitamins, phosphates, acids, antioxidants, etc., which are nutritional and health benefits to the body $[12,13]$.

Carbonated drink in the Nigerian market has been controlled since the 1950 s by big international beverage drink company. Their brands have been a delight for the end-user of all ages. In 1953 Coca-Cola was introduced in Nigeria, while in 1960, 7ups was first introduced. PepsiCo later managed 7up from 1990. The exemplary Coca-Cola brands and the ever tenacious PepsiCo brands have controlled the Nigerian carbonated soft drink market for so long a time. Even when other brands try to maintain their unique selling ability to the consumers, the Cola-Cola and PepsiCo brands have always stormed different competition weather from year to year. Down the memory line from the '80s came Dr Pepper, AfriCola, Canada Dry, Limca, Tandi, Brahma e.t.c. They all came and were dominated by the two biggest brands. It had been a two straight rivalry, contenting in vigour-to-vigour, and weakness-to-weakness. Coke vs Pepsi, 7-Up vs Sprite, Fanta vs Mirinda and Schweppes vs Teem competed for dominant. Soft drinks were packed in returnable and reusable glass bottles, until the year 2001, immediately the La'Casera brands introduced its Apple brand, it grew in popularity.

La'casera brand was the first to spread carbonated PET jug drink in Nigeria. The shoppers found another adoration in Pet jug, and the two warriors followed suits in dispatching theirs in 2004. The warmth of the opposition was turned on purchasers selling techniques and different pressing medium and sizes: glass bottle $(33 \mathrm{cl}),(50 \mathrm{cl})$ and pet jug $(50 \mathrm{cl})$ and aluminium jars $33 \mathrm{cl}$. The customer experience was uplifted, and the shoppers' decision got limitless. For over ten years, different market measurements demonstrated the La'casera brands gave a decent rivalry to Coca Cola and Pepsico, with La'Casera pet jug's presentation. However, for a few years now the La'Casera brands have been slackening its steam because of buyers developing complex culture, taste and some inside emergency in the La'casera Company. This license the agelong strength of the two combatants in the Nigeria carbonated soda pop market. At that point from a safe house came the Aje brand of Big. The Big Cola, Big Orange. Their selling point is the presentation of $65 \mathrm{cl}$ pet container which gave buyers' perpetual freedom of decision. A new market study showed that Aje large brand appreciates critical support even inside its brief timeframe of market dispatch. Although PepsiCo reacted with $60 \mathrm{cl}$ jug presentation, Aje novel "large' of $65 \mathrm{cl}$ is making shoppers' compassion and new customer experience. Over a couple of months, the early market participants returned to their unique $50 \mathrm{ml}$ pet sizes, while Aje Big proceeded with its exceptional $65 \mathrm{ml}$. In these, the purchaser is the champ. The crises of new brands made annihilation in the buyers' market, with the introduction of Aje Big, King Soda, Frizz, and Rite's Bigi mark generally in the PET jug section. Ritual's Bigi carbonated sodas' appearance is valued by numerous purchasers, pressed in $60 \mathrm{ml}$ PET jug. Rituals are the proprietors of Bigi brands, a grounded wheat flour-based, meat-filled prepared hotdog move snacks pulverised the wiener move market six years back. The Rite Group recently dispatched Rite's Bigi sodas into Nigeria [14].

An analysis aimed at establishing whether the concentrations of harmful metals in soft drinks usually taken are the lower or upper limit for all the metals set by the World Health Organization (WHO). Twenty (20) brands of soft drinks commonly consumed in Lagos, Nigeria, for the presence of lead, cadmium, nickel, silver, chromium and zinc applying standard biochemical procedures were examined. Results indicated that cadmium was present in four samples at a concentration ranging from 0.023 to $0.158 \mathrm{mg} / \mathrm{L}$. The lead was discovered in three of the samples at an absorption level from 0.5045 to $3.0275 \mathrm{mg} / \mathrm{L}$, and nickel was seen in six of the samples at an absorbing level from 0.016 to $0.063 \mathrm{mg} / \mathrm{L}$ while silver was not seen in all of the samples [15]. Constituents of twenty-five (25) soft drinks in Nigeria was evaluated and reviewed for the presence of some heavy metal. The soft drinks were tested for sugar, carbon dioxide, phosphate, alcohol, PH and acidity resolved. The amount of cadmium, mercury and lead were established using atomic absorption spectrophotometer. The result revealed sugar, carbon dioxide, phosphate, and alcohol in soft drinks. Activity, PH ranging from 3 to 5 with an average of 3.6 and the acid concentration was small between 3 and $12 \mathrm{~g} / \mathrm{L}$ with $8.1 \mathrm{~g} / \mathrm{L}$ presents in the soft drinks [8]. Aloh et al. [16] determined the type and quantity of sugar present in each of the two soft drinks. Knight and Alien EDTA methods determined the type of sugar present; the result showed that all the brands of soft drinks tested contained sucrose as the only sugar present. The sugar level and the densities varied through the brands in the order. Pepsi>Coke>Gold

Sport $>$ Limca $>$ Sprite $>7$ up $>$ Fanta $>$ Miranda. The mean sugar concentration for all the soft drinks in Ebonyi State was $32.4856 \mathrm{mg}$. Though there were differences between the sugar values, it still falls within an acceptable limit. The soft drinks were all acidic at room temperature. The quantity of sugar in carbonated water and fruit juices was obtained by density and refractometric methods. Also, the number of different sugars were determined using infrared spectroscopy coupled with PLS analysis. The result indicated that sucrose is critical in sugar-added organic product juices (FJ1-FJ6), and there is no sucrose in non-sugar-added juices (FJ7-FJ10). Besides, the measure of fructose is higher in sodas contrasted with sugar added juices [17]. Sodamade [18] examined ten (10) samples of soft drinks available in Nigerian markets and analysed total soluble sugars using the spectrophotometric technique. The result showed that the soft drinks' sugar contents range between $9.91+0.0141 \mathrm{~g} / 100 \mathrm{ml}$ in $\mathrm{A} 1$ to $13.55+0.0071 \mathrm{~g} / 100 \mathrm{ml}$ in A3. These selected samples' sugar contents were within the specified standard of Nigeria's standard organisation of $7.00-$ $14.00 \mathrm{~g} / 100 \mathrm{ml}$. Martin-Villa et al. [19] analysed the qualitative and quantitative composition of soluble carbohydrates consumed in sixteen (16) soft drinks. The conditional analysis was carried out by thin-layer chromatography while the quantitative resolution was performed by column chromatography and spectrophotometric method. Most of the soft drinks analysed contain the monosaccharides glucose, fructose and disaccharide sucrose while the quantity of these sugars differs from bottle to bottle. The content of total soluble carbohydrates of most of the drinks analysed is rather high. It 
may represent an important caloric supplement in the diet, considering the high consumption of these drinks by the Spanish population. Idris et al. [20] determine the amount of sugar and PH in financially available soft drinks in Jazan, Saudi Arabia. It further compared their labelled quality to inform the regulations. The result indicated that calculated sugar in energy drinks $(14.3 \pm 0.48$ and $15.6 \pm 2.3$, respectively) was larger than the carbonated drinks (11.2 \pm 0.46 and $12.8 \pm 0.99$ ), which was significant statistically. The result also indicated that; there was a significant difference between the consolidation of glucose in energy drinks (5.7 \pm $1.7)$ and the carbonated $(4.1 \pm 1.4)$. The $\mathrm{PH}$ of these drinks limits from 2.4 to 3.2. There existed a statistically significant difference in the estimated and labelled sugar in carbonated drinks. Orav and Kann [21] studied the numeric and nonnumeric difference between volatile aroma compounds in different foods and beverages comprising peppermint and orange aroma using the simultaneous distillation and extraction micro techniques for isolating the fraction capillary gas chromatography for analysing the extracts. There are 41 ingredients in aroma and in the orange aroma of which, twenty-two (22) compounds were identified, the yields of aroma fractions from different materials changes from 0.2 up to $24 \mathrm{mg} / \mathrm{g}$ (peppermint) and from $0.03 \mathrm{up}$ to $2 \mathrm{mg} / \mathrm{g}$ (orange). Onyemelukwe et al. [22] study sugar and caloric contents of soft drinks marketed in Nigeria. Six (6) different brands of soft drinks marketed all over Nigeria were analysed for their sugar (glucose, fructose and sucrose) and caloric contents. It was discovered that the sugar content ranges between 3.29 to 7.70 grams per bottle with a caloric value ranging between 13.2 and 30.8 kilocalories per bottle. Imamura et al. [23] studied the possible relationship between demand for sugar-sweetened beverages, artificially sweetened beverages, and fruit juice with type 2 diabetes before and after adiposity adjustment was examined. Survey analysis and random-effects meta-analysis and for population peculiarity associated with the consumption of sugar-sweetened beverages. Pre-specified information was extracted from 17 cohorts (38253 cases/10126754 person-years). The result shows that higher consumption of sugar-sweetened beverages was associated with a greater incidence of type 2 diabetes.

The literature reviewed has not discussed the significant chemical structures present in the soft drinks sold and consumed in Nigeria. It has not also shown the distribution of chemical compositions in the soft drinks based on their components. Therefore, this research is set out to study the significant chemical compositions present in the twenty - five (25) soft drinks and the distribution of chemical compositions based on the Principal components. It will also try to fill the identified gaps in the literature with updated data and methodology.

This study's main purpose is to define the clusters of soft drinks in Nigeria explicitly, to determine the relationship between the chemical compositions of the twenty-five (25) soft drinks, ascertain the components to be retained and distribute the chemical composition into specific components. The materials and methods are described in Section 2 of the study. Section 3 presents data analysis and interpretation, and finally, conclusions and recommendations are presented in section 4 .

\section{MATERIALS AND METHODS}

\subsection{Source of data}

Sample concentration of twenty-five (25) soft drinks was used in this study, and the sample concentration was collected from the National Agency for Food and Drug Administration and Control [24].

\subsection{Principal component analysis}

Principal Component Analysis is a multivariate methodology used for changing a set of correlated variables into a set of uncorrelated variables that explains the decreasing proportions of the change in the original observations [25]. Suppose the first few derived variables (the principal components) account for a large proportion of the observed variables' total variance. In that case, they can provide a convenient summary of the data and simplify subsequent analysis. Algebraically, the principal component is the linear combinations of the $\mathrm{p}$ random variables $X_{1}, X_{2}, \ldots, X_{p}$. Geometrically, these linear combination is the picking of a new coordinate order obtained by rotating the original system with $X_{1}, X_{2}, \ldots, X_{p}$ as the coordinate axes. The new axes represent the directions with maximum variability and provide a simpler and more parsimonious description of the covariance structure [26]. Principal components rest entirely on the covariance matrix $\boldsymbol{\Sigma}$ (or the correlation matrix $\rho$ ) of $X_{1}, X_{2}, \ldots, X_{p}$

Suppose $X$ is a vector of $p$ random variables, the function of the principal component analysis transformation is to search for a few $(<p)$ derived variables that save most of the information given by the variance of the $p$ random variable [27]. Let the random vector $X^{\prime}=\left[X_{1}, X_{2}, \ldots, X_{p}\right]$ have the covariance matrix $\Sigma$ with eigenvalues $\lambda_{1} \geq \lambda_{2} \geq \ldots \geq$ $\lambda_{p} \geq 0$.

Consider the linear combinations;

$$
\begin{aligned}
& Y_{j}=\alpha_{j}^{\prime} X=\alpha_{j 1}^{\prime} X_{1}+\alpha_{j 1}^{\prime} X_{1}+\ldots+\alpha_{j p}^{\prime} X_{p} \\
& =\sum_{i=1}^{p} \alpha_{j k} X_{k}, j=1,2, \ldots, p, \text { of the element of } X
\end{aligned}
$$

where, $\alpha_{j}$ is a vector of $p$ components $\alpha_{j 1}, \alpha_{j 2}, \ldots, \alpha_{j p}$. Then,

$$
\begin{gathered}
\operatorname{Var}\left(Y_{j}\right)=\alpha_{j}^{\prime} \sum \alpha_{j} \quad j=1,2, \ldots, p \\
\operatorname{Cov}\left(Y_{j,} Y_{k}\right)=\alpha_{j}^{\prime} \sum \alpha_{k} \quad j, k=1,2, \ldots, p
\end{gathered}
$$

The PCs are those unrelated linear combinations $Y_{1}, Y_{2}, \ldots$, $Y_{p}$ whose variances in (2) are as large as possible [28]. In finding the principal components, the variance is considered. The first stage is to look for a linear combination $\alpha_{1}^{\prime} X$ with maximum variance, so that;

$$
\alpha_{1}^{\prime} X=\alpha_{11} X_{1}+\alpha_{12} X_{2}+\ldots+\alpha_{1 p} X_{p}=\sum_{i=1}^{p} \alpha_{1 k} X_{k}
$$

The linear combination $\alpha_{2}^{\prime} X$ uncorrelated with $\alpha_{1}^{\prime} X$ have a maximum variance and at the $k^{\text {th }}$ stage a linear combination 
$\alpha_{k}^{\prime} X$ is discovered to have a maximum variance subject to being uncorrelated with $\alpha_{1}^{\prime} X, \alpha_{2}^{\prime} X, \ldots, \alpha_{K-1}^{\prime} X$. The $k^{\text {th }}$ derived variable $\alpha_{k}^{\prime} X$ is the $k^{\text {th }}$ principal components [29]. Up to $p^{\text {th }}$ principal components could be found, but we have to stop after the $q^{\text {th }}$ stage $(q \leq p)$ when most of the $\mathrm{X}$ changes have been accounted for by $q$ principal components.

The variance of principal components is equal to the eigenvalue corresponding to that principal components;

$$
\operatorname{Var}\left(Y_{j}\right)=\alpha_{j}^{\prime} \sum \alpha_{j}=\lambda_{j} \quad j=1,2, \ldots, p
$$

The total variance in observation is equal to the total variance of the principal components

$$
\begin{aligned}
\sigma_{11}+\sigma_{22}+\ldots+\sigma_{p p} & \\
& =\sum_{j=1}^{p} \operatorname{Var}\left(X_{j}\right) \\
& =\lambda_{1}+\lambda_{2}+\ldots+\lambda_{p} \\
& =\sum_{j=1}^{p} \operatorname{Var}\left(Y_{j}\right)
\end{aligned}
$$

The data is standardised for the variables to have the same scale using a common standardisation method of transforming observations to have zero mean and unit standard deviation [30]. For a random vector $X^{\prime}=\left[X_{1}, X_{2}, \ldots, X_{p}\right]$ the corresponding standardised variables are;

$$
Z=\left[Z_{j}=\frac{\left(X_{j}-\mu_{j}\right)}{\sqrt{\sigma_{j j}}}\right] j=1,2, \ldots, p
$$

In matrix notation,

$$
Z=\left(V^{1 / 2}\right)^{-1}(X-\mu)
$$

where, $V^{1 / 2}$ Is the diagonal standard deviation matrix. Thus and $E(Z)=0$ and $\operatorname{COV}(Z)=\rho$.

The principal components of $Z$ can be obtained from the eigenvectors of the correlation matrix $\rho$ of $X$. The previous properties for $X$ are applied to the $Z$ so that the notation $Y_{j}$ refers to the $j^{\text {th }}$ principal components and $\left(\lambda_{j}, \alpha_{j}\right)$ Refers to the eigenvalue-eigenvector pair. However, the quantities derived from $\Sigma$ are different from those derived from $\rho$ [28]. The $j^{\text {th }} \mathrm{PC}$ of the standardised variables $Z^{\prime}=\left[Z_{1}, Z_{2}, \ldots, Z_{P}\right]$ with $\operatorname{Cov}(Z)=\rho$ is given by;

$$
Y_{j}=\alpha_{j}^{\prime} Z=\alpha_{j}^{\prime}\left(V^{1 / 2}\right)^{-1}(X-\mu)
$$

So that

$$
\sum_{j=1}^{p} \operatorname{Var}\left(Y_{j}\right)=\sum_{j=1}^{p} \operatorname{Var}\left(Z_{j}\right)=P \quad j=1,2, \ldots, p
$$

Therefore, $\left(\lambda_{1}, \alpha_{1}\right),\left(\lambda_{2}, \alpha_{2}\right), \ldots,\left(\lambda_{p}, \alpha_{p}\right) \quad$ are the eigenvalue-eigenvector pairs for $\rho$ with $\lambda_{1} \geq \lambda_{2} \geq \ldots \geq \lambda_{p} \geq$ 0 .

\subsection{Interpretation of principal components results}

The loading or the eigenvector $\alpha_{j}=\alpha_{1}, \alpha_{2}, \ldots, \alpha_{p}$, can be characterised as the proportion of the importance of a variable in a given principal component. When all elements of $\alpha_{1}$; are positive, the main segment is a weighted normal of the factors, and it can be referred to as a measure of overall soft drink composition. Similarly, the positive and negative coefficients in propose components can be regarded as the different chemical composition $[25,29,31]$. The next procedure finds a second linear combination, uncorrelated with the first component, such that it accounts for the next largest amount of variance (after the variance attributable to the first component has been removed) in the system [32].

The new principal component observations $Y_{i j}$ are gotten basically by subbing the first factor $X_{i j}$ into the set of the first $q$ PCs.

$$
\begin{gathered}
Y_{i j}=\alpha_{j 1}^{\prime} X_{i 1}+\alpha_{j 2}^{\prime} X_{i 2}+\ldots+\alpha_{j p}^{\prime} X_{i p}, i=1,2, \ldots, n, \\
j=1,2, \ldots, p
\end{gathered}
$$

The plot of the second or third PCs against each other enhances visual interpretation [33].

\subsection{The proportion of variance}

The proportion of variance describes the principal components that best explained the original variables. It is a degree of how well the first $q$ principal components of $\mathrm{Z}$ explain the variation is given by;

$$
\psi_{q}=\frac{\sum_{j=1}^{q} \lambda_{j}}{p}=\frac{\sum_{j=1}^{q} \operatorname{Var}(Z)}{p}
$$

cumulative proportion of explained variance is an important criterion for determining the number of components to be preserved in the analysis. A Scree plot gives an outstanding graphical presentation of the principal components' potency to explain the variation in an observation [34].

\section{DATA ANALYSIS AND INTERPRETATION}

The first result from the analysis in Table 1 is the descriptive statistics for all the composition of the soft drinks, from the result, sucrose is the essential chemical composition of soft drinks because it has the highest mean of 3.7564 .

Table 2 presents the correlation matrix of the chemical compositions of the twenty-five (25) drinks. The result shows that; carbonated water has a significantly strong positive association with fructose, sucrose, main concentrations, stabilisers, E412 and colouring, and a weak positive correlation with gelatin. Fructose has a significantly strong positive relationship with sucrose, main concentrations, stabilisers, E412, colouring and gelatin. There existed a strong positive association between main concentrations, stabilisers, E412 and colouring. Main concentration has a significantly strong positive correlation between and stabilisers, E412, colouring and gelatin. The preservative has a significant relationship with antioxidant, and the stabiliser has a significant relationship with E412, colouring and gelatin, E412 has a significant relationship with colour. Gelatin has a significant positive relationship with colouring. In contrast, acidity and antioxidant have no significant relationships with other chemical composition. All except acidity and antioxidant have a significantly strong positive relationship which implies that all these chemical compositions are significantly and 
positively related; hence, a rise in one may lead to an increase in another.

In the result presented in Table 3, the null hypothesis which states that the Correlation matrix is an identity matrix was rejected at 5\% level of significance (Bartlett's test of Sphericity; $\chi 2=350.897$, $\mathrm{p}$-value $=0.000$ ), this implies that the correlation in the observation is appropriate for factor analysis. Also, "Kaiser-Meyer-Olkin statistic $=.748$ " revealed that adequate sampling is being used for this analysis.

Communities of the chemical ingredients of the $25 \mathrm{soft}$ drinks are present in Table 4, and this is the ratio of each variable's variance explained by the chemical compositions. The result indicated that over $90 \%$ of the variance in carbonated water, fructose, stabiliser and E412 was accounted for in each drink. The result also showed that over $80 \%$ of the main concentration variance, preservative, antioxidant, colouring, and gelatin is accounted for. In contrast, over $70 \%$ of the glucose and sucrose was accounted for. All chemical compositions of the twenty-five (25) soft drinks except acidity has explained variance higher than 0.5 (minimum value), this led to the removal of acidity from the analysis.

The result of the eigenvalues and the cumulative proportions of the explained variance are displayed in Table 5. Considering the eigenvalue criterion and the Scree plot in
Figure 1, it would be reasonable to retain the first three principal components. The decision rule says that it is sufficient to keep only principal components with eigenvalues larger than 1 . The first three principal components can be retained to explain 82.465 per cent of the total variability.

Table 6 and Figure 2 present the concentrations and loading of soft drinks' chemical components in the three principal components that explain 82.465 per cent of the total variability in the retained data set.

Component one (1): Fanta, seven-up, coke, light coke, diet coke, teem, sprite, Mirinda has a strong positive relationship with carbonated water, fructose, sucrose, main concentration, stabiliser, E412, colouring and gelatin as the primary chemical compositions of the soft drinks in these components and an inverse relationship with; glucose, preservative and antioxidant.

Component two (2): Schweppes, limca, Afri-cola, Pepsi, Maltina, Maltonic, Amstel, malt, hi malt; identified glucose, preservative and antioxidant as the significant soft drink chemical compositions.

Component three (3): 5-live, chivita, vital milk, mountain dew, krest, soda water, Fanta tonic, Fanta Lemon, Fanta pineapple; identified colouring and gelatin as the chemical composition in the soft drinks under this component.

Table 1. Descriptive analysis

\begin{tabular}{cccccccccc}
\hline Composition & N & Minimum & Maximum & Mean & Std. Dev. & Skewness & Kurtosis \\
\hline carbon.water & 25 & 1.05 & 3.95 & 1.5861 & .79342 & 2.058 & .464 & 3.702 & .902 \\
Glucose & 25 & .26 & .76 & .4144 & .11951 & 1.173 & .464 & 1.728 & .902 \\
Fructose & 25 & .04 & 3.51 & .7349 & 1.01445 & 1.682 & .464 & 2.032 & .902 \\
Sucrose & 25 & .04 & 13.79 & 3.7564 & 4.12300 & 1.116 & .464 & .411 & .902 \\
Main contr. & 25 & .00 & 2.03 & .4677 & .55991 & 1.754 & .464 & 2.432 & .902 \\
Acidity & 25 & .00 & 6.37 & .6464 & 1.26107 & 4.213 & .464 & 19.347 & .902 \\
Preservative & 25 & .48 & 18.03 & 2.1856 & 3.43302 & 4.423 & .464 & 20.894 & .902 \\
Stabilizer & 25 & .03 & 9.10 & 1.5681 & 2.26762 & 1.955 & .464 & 4.082 & .902 \\
E412 & 25 & .02 & 4.94 & .8036 & 1.10654 & 2.548 & .464 & 7.675 & .902 \\
Antioxidant & 25 & .02 & 5.58 & .7164 & 1.27335 & 2.770 & .464 & 8.556 & .902 \\
Colouring & 25 & .07 & 8.73 & 1.8064 & 2.47310 & 1.894 & .464 & 2.891 & .902 \\
Gelatin & 25 & .02 & 5.41 & 1.4804 & 1.34740 & 1.179 & .464 & 1.379 & .902 \\
\hline
\end{tabular}

Table 2. Correlation matrix

\begin{tabular}{|c|c|c|c|c|c|c|c|c|c|c|c|c|}
\hline Compositions & Carb. & Glucose & fructose & sucrose & Main & Acidity & Pres. & Stab. & E412 & Anti. & Col. & Gel. \\
\hline Carb.water & 1 & & & & & & & & & & & \\
\hline Glucose & -0.117 & 1 & & & & & & & & & & \\
\hline Fructose & $.966 * *$ & -0.101 & 1 & & & & & & & & & \\
\hline Sucrose & $.798 * *$ & -0.262 & $.831 * *$ & 1 & & & & & & & & \\
\hline Main & $.917 * *$ & -0.116 & $.904 * *$ & $.744 * *$ & 1 & & & & & & & \\
\hline Acidity & -0.101 & -0.047 & -0.125 & -0.165 & -0.12 & 1 & & & & & & \\
\hline Preservative & -0.116 & $.740 * *$ & -0.134 & -0.171 & -0.13 & 0.012 & 1 & & & & & \\
\hline Stabilizer & $.938 * *$ & -0.035 & $.971 * *$ & $.813 * *$ & $.843 * *$ & -0.122 & -0.081 & 1 & & & & \\
\hline E412 & $.923 * *$ & -0.031 & $.938 * *$ & $.786 * *$ & $.796 * *$ & -0.113 & -0.073 & $.980 * *$ & 1 & & & \\
\hline Antioxidant & -0.17 & $.647 * *$ & -0.154 & -0.242 & -0.19 & -0.019 & $.865^{* *}$ & -0.132 & -0.11 & 1 & & \\
\hline Colouring & $.607 * *$ & -0.106 & $.675^{* *}$ & $.544 * *$ & $.540 * *$ & -0.184 & -0.203 & $.577 * *$ & $.478 *$ & -0.184 & 1 & \\
\hline Gelatin & $.470 *$ & -0.223 & $.492 *$ & 0.369 & $.423 *$ & -0.104 & -0.343 & $.397 *$ & 0.315 & -0.361 & $.827 * *$ & 1 \\
\hline
\end{tabular}

** Correlation is significant at the 0.01 level of significance (2-tailed). * Correlation is significant at the 0.05 level of significance

Table 3. KMO and Barlett's test

\begin{tabular}{lcc}
\hline \multicolumn{2}{c}{ Kaiser-Meyer-Olkin Measure of Sampling Adequacy. } & $\mathbf{0 . 7 4 8}$ \\
\hline & Approx. Chi-Square & 350.897 \\
\multirow{2}{*}{ Bartlett's Test of Sphericity } & Df & 66 \\
& Sig. & 0.000 \\
\hline
\end{tabular}


Table 4. Communalities

\begin{tabular}{ccc}
\hline Compositions & Initial & Extraction \\
\hline Carbonate wat. & 1.000 & .955 \\
Glucose & 1.000 & .761 \\
Fructose & 1.000 & .985 \\
Sucrose & 1.000 & .769 \\
Main & 1.000 & .833 \\
Acidity & 1.000 & .299 \\
Preservative & 1.000 & .896 \\
Stabilizer & 1.000 & .958 \\
E412 & 1.000 & .926 \\
Antioxidant & 1.000 & .841 \\
Colouring & 1.000 & .856 \\
Gelatine & 1.000 & .818 \\
\hline
\end{tabular}

Table 5. Eigenvalues

\begin{tabular}{cccc}
\hline \multirow{2}{*}{ Compositions } & \multicolumn{3}{c}{ Initial Eigenvalues } \\
\cline { 2 - 4 } & Total & \% of variance & Cumulative \% \\
\hline Carbonated water & 6.253 & 52.111 & 52.111 \\
Glucose & 2.498 & 20.819 & 72.930 \\
Fructose & 1.144 & 9.535 & 82.465 \\
Sucrose & .933 & 7.779 & 90.244 \\
Main & .410 & 3.421 & 93.664 \\
Preservative & .217 & 1.811 & 97.626 \\
Stabilizer & .147 & 1.221 & 98.848 \\
E412 & .085 & .712 & 99.559 \\
Antioxidant & .037 & .306 & 99.865 \\
Colouring & .009 & .076 & 99.942 \\
Gelatin & .007 & .058 & 100.000 \\
\hline
\end{tabular}

Table 6. Eigenvectors

\begin{tabular}{cccc}
\hline & \multicolumn{3}{c}{ Component } \\
\cline { 2 - 4 } & $\mathbf{1}$ & $\mathbf{2}$ & $\mathbf{3}$ \\
\hline Carbonated water & $\mathbf{0 . 9 5 6}$ & 0.166 & -.119 \\
Glucose & -.231 & $\mathbf{0 . 8 1 4}$ & 0.211 \\
Fructose & $\mathbf{0 . 9 7 5}$ & 0.171 & -.068 \\
Sucrose & $\mathbf{0 . 8 6 4}$ & 0.036 & -.145 \\
Main concentrate & $\mathbf{0 . 8 9 5}$ & 0.133 & -.121 \\
Preservative & -.276 & 0.903 & 0.067 \\
Stabilizer & $\mathbf{0 . 9 3 9}$ & 0.232 & -.149 \\
E412 & $\mathbf{0 . 9 0 0}$ & 0.250 & -.232 \\
Antioxidant & -.315 & $\mathbf{0 . 8 5 5}$ & 0.104 \\
Colouring & $\mathbf{0 . 7 2 9}$ & -.065 & $\mathbf{0 . 5 6 6}$ \\
Gelatin & $\mathbf{0 . 6 0 2}$ & -.295 & $\mathbf{0 . 6 0 7}$ \\
\hline
\end{tabular}

Extraction Method: Principal Component Analysis.

a. three components extracted.

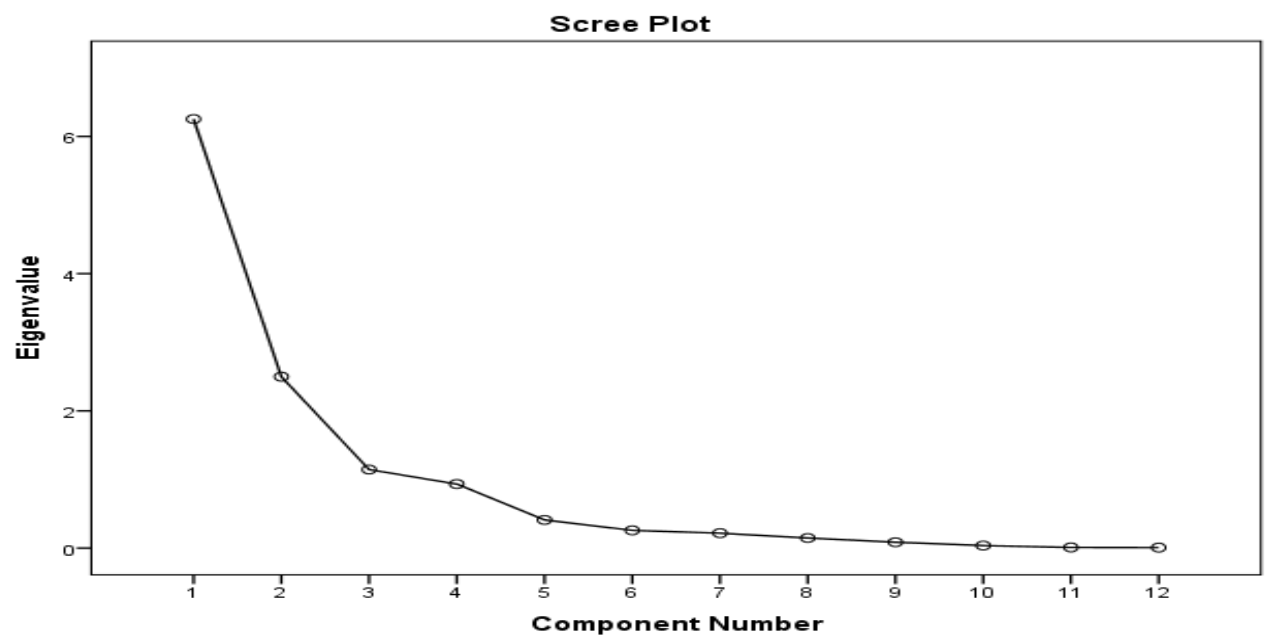

Figure 1. Scree plot

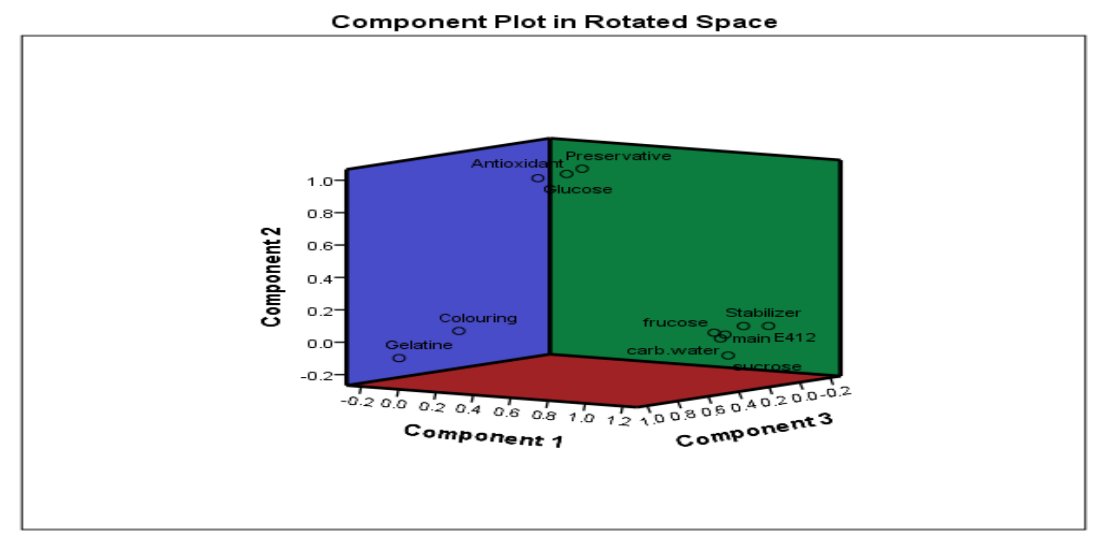

Figure 2. Component plot in rotated space 


\section{CONCLUSIONS AND RECOMMENDATIONS}

Principal Component Analysis (PCA) is an effective means of reducing the dimension of a large set of variables to a small number of factors. In this study, twelve (12) chemical compositions of 25 soft drinks samples sold in Nigeria since the last twenty (20) years was considered. The results showed that all except acidity and antioxidant has a significantly strong positive relationship among the chemical compositions. The proportion of the variable's variance that can be interpreted or explained by the chemical compositions indicated that all chemical composition except acidity is higher than 0.5 . Therefore, principal Component Analysis suggested removing acidity from the analysis and retainment of the first three principal components because it explained up to 82.465 per cent of the total variability. It was also observed that carbonated water, fructose, sucrose, main concentration, stabiliser, E412, colouring and gelatin were the significant compositions of soft drinks in Nigeria because they had a strong positive (greater than 0.5) Eigenvectors.

The distribution of the chemical compositions of soft drinks in Nigeria indicated that; carbonated water, fructose, sucrose, main concentration, stabiliser and E412 were the significant compositions of Fanta, seven-up, coke, light coke, diet coke, teem, sprite, Mirinda. Schweppes, limca, Afri-cola, Pepsi, Maltina, Maltonic, Amstel malt, and Hi malt had high antioxidant, preservative, and glucose loading. In contrast, 5live, chivita, vital milk, mountain dew, krest, soda water, Fanta tonic, Fanta Lemon, Fanta pineapple had high loading in colouring and gelatin as the significant soft drink chemical compositions.

Base on the findings in this study, the following recommendations are suggested. Customers who are allergic to sugar or diabetic should avoid taking any of the soft drinks listed under component one (1) because of a high sugar concentration. For energy requirement, consumers should consider taking drinks with high scores in component two (2). Soft drinks companies producing drinks with high sugar content should consider their customers who are diabetic and allergic to high sugar levels.

\section{ACKNOWLEDGEMENT}

The authors acknowledge the Department of Statistics, Faculty of Science, University of Abuja, Nigeria, for their support and encouragement throughout the period of writing this research.

\section{REFERENCES}

[1] Gatenby (2003). Encyclopedia of Food Sciences and Nutrition (Second Edition). Elsevier Science Ltd.

[2] Jacqueline B.M. (2013). MS, RD, LD, CNS, FADA. Culinary Nutrition, Elsevier/Academic Press.

[3] Wedzicha, B.L (2003). Encyclopedia of Food Sciences and Nutrition (Second Edition). https://www.sciencedirect.com/science/article/pii/B012 227055X00969X.

[4] Stratford, M., Capell, C.J. (2003). Encyclopedia of Food Sciences and Nutrition (Second Edition). https://www.sciencedirect.com/science/article/pii/B012 227055 X011032.
[5] Jorge, K. (2003). Encyclopedia of Food Sciences and Nutrition (Second Edition). https://doi.org/10.1016/B012-227055-X/01101-9

[6] Kirk, R.S., Sawyer, R., Pearson, D. (1991). Composition and Analysis of Foods, 9th Edition. Harlow: Longman Scientific and Technical.

[7] Ambler, T., Styles, C. (1996). Brand development versus new product development: Toward a process model of extension decisions. Marketing Intelligence \& Planning, 14(7): 10-19. https://doi.org/10.1108/02634509610152664

[8] EFSA (European Food Safety Authority). (2011). The setting of nutrient profiles for foods Bearing nutrition and health claims pursuant to Article4 of the Regulation (EC.) No 1924/2006: Scientific opinion of the panel on dietetic products, nutrition and allergies. EFSA Journal, 6(2). https://doi.org/10.2903/j.efsa.2008.644

[9] Dharmasena, K.A. (2010). The non-alcoholic beverage market in the united states: demand interrelationships, dynamics, nutrition issues and probability forecast evaluation ( $\mathrm{PhD}$ thesis). Texas A\&M University. http://hdl.handle.net/1969.1/ETD-TAMU-2010-05-7911.

[10] Phillip, B.B., Shittu, A.M., Ashaolu, O.F. (2013). Demand for Non-Alcoholic beverages among urban households in South West, Nigeria. African Journal of Food Agriculture and Nutritional Development, 13(3): 7853-7869.

[11] Asiegbu, I.F., Awa, H.O., Akpotu, C., Ogbonna U.B. (2011). Salesforce competence development and marketing performance of industrial and domestic products firms in Nigeria. Far East Journal of Psychology and Business, 2(4): 43-59.

[12] Pofahl, G.M., Capps O., Jr., Clauson, Jr. A. (2005). Demand for Non-Alcoholic beverages: Evidence from the AC-Nelson Home scan panel. Paper Presented at the American Agricultural Economics Association Annual Meeting, Providence, Rhode Island. https://doi:10.22004/ag.econ.19441

[13] Engwa, A. G., Ihekwoaba, C. J., Ilo, U. S., Unaegbu, M., Ayuk, L. E., Osuji, A. G. (2015). Determination of some soft drink constituents and contamination by some heavy metals in Nigeria, Toxicology Report, 2: 384-390. https://doi.org/10.1016/j.toxrep.2015.01.014

[14] Jimoh, J.K. (2015). Dynamism in Nigerian Carbonated Soft Drink Market. Linkedin. https://www.linkedin.com/pulse/big-war-nigeriancarbonated-soft-drink-market-jimoh-jelili-kolawole.

[15] Adepoju-Bello, A.A., Oguntibeju, O.O., Onuegbu, M.T., Ayoola, G., Coker, H. (2012). Analysis of selected metallic impurities in soft drinks marketed in Lagos, Nigeria. African Journal of Biotechnology, 11(20): 46764680.

[16] Aloh, G.S., Obeagu, E.I., Ifeanyi, Emeka, O.C., Kanu, S., Ngozika, Ezechukwu, K.O., Ezechukwu, Nka, J., Sunday. (2015). Estimation of Sugar in Soft Drinks. World Journal of Pharmacy and Pharmaceutical Sciences, 4(3): 112-125. https://www.researchgate.net/publication/301327449_E STIMATION_OF_SUGAR_IN_SOFT_DRINKS.

[17] Ramasami, P., Jhaumeer-Laulloo, S., Rondeau, P., Cadet, F., Seepujak H., Seeruttun, A. (2004) Quantification of sugars in soft drinks and fruit juices by density, refractometry, infrared spectroscopy and statistical methods. South Africa Journal of Chemistry, 57: 24-27. 
[18] Sodamade, A. (2012). Assessment of sugar levels in different soft drinks: A measure to check national food security. International Journal of Science and Research (IJSR), 3(12): 567-569.

[19] Martin-Villa, M.C., Vidal-Valverde, C., Rojas-Hidalgo, E. (1981). Soluble sugars in soft drinks. The America Journal of Clinical Nutrition, 34(10): 2151-2153. https://doi:10.1093/ajen/34.10.2151

[20] Idris, A.M., Vani, N.V., Almutari, D.A., Jafar, M.A., Boreak, N. (2016). Analysis of sugars and PH in commercially available soft drinks in Saudi Arabia with a brief review of their dental implications. Journal of International Society of Preventive and Community Dentistry, 6(9): 192-196. https://doi:10.4103/22310762.197190

[21] Orav, A., Kann, J. (2001). Determination of peppermint and orange aroma compounds in food and beverages using cluster analysis. Proc. Estonian Acad. Sci. Chem., 2001, 50(4): 217-225.

[22] Onyemelukwe, G.C., Bakari, A.G., Ogbadu, G. (2006). Simple sugar and caloric contents of soft drinks in Nigeria. International Journal of Diabetes \& Metabolism, 14(2): 110-111.

[23] Imamura, F., O'Connor, L., Ye, Z., Mursu, J., Hayashino, Y., Bhupathiraju, S.N., Forouhi, N.G. (2015). Consumption of sugar-sweetened beverages, artificially sweetened beverages, and fruit juice and incidence of type 2diabetes: A systematic review, meta-analysis, and estimation of population attributable fraction. The British Medical Journal. https://doi.org/10.1136/bmj.h3576

[24] NAFDAC. (2018). National Agency for Food and Drug, Administration and Control. Home drugs and Medical Device Drug Data database. (January-December, 2018) www.nafdac.gov.ng.

[25] Rencher, A.C. (2002) Methods of Multivariate Analysis. $2^{\text {nd }}$ edition. John Wiley \& Son, New York.
[26] Osuji. G.A., Obubu. M., Obiora-Ilouno. H.O. (2015). An Investigation on crime rate in South-eastern Nigeria. European Journal of Statistics and Probability, 3(4): 1-9.

[27] Jolliffe, I.T. (2002). Principal Component Analysis. 2nd edition, Springer-Verlag, New York.

[28] Richard, A.J., Dean, W.W. (2001). Applied Multivariate Statistical Analysis. 3rd edition, Prentice-Hall, New Delhi.

[29] Nasiru M.O., Adams, S.O., Olanrewaju. S.O. (2017). Principal component analysis of crime data in Gwagwalada Area Command, Abuja from 1995 - 2015. American Journal of Theoretical and Applied Statistics, 6(1): 38-43. https://doi:10.11648/j.ajtas.20170601.15

[30] Adams, S.O., Bamanga, M.A., Mbusube, A. (2019). Principal component analysis of Nigerian economy from 2006 - 2017. Asian Journal of Advanced Research and Reports, 5(4): 1-9. https://doi.org/10.9734/ajarr/2019/v5i430139

[31] Gulumbe, S.U, Dikko, H.G., Bello, Y. (2013). Analysis of crime data using principal component analysis: A case study of Katsina State. CBN Journal of Applied Statistics, 3(2): 39-49.

[32] Pituch, K.A., Stevens, J.P. (2012) Applied Multivariate Statistics for the Social Sciences. 6th Edition. Analysis with SAS and IBM'S SPSS. Routledge, Taylor \& Francis Group. Newyork and London: http://docshare02.docshare.tips/files/31719/317194846.p df.

[33] Schiegel, A. (2017). Principal Component Analysis with R Example. https://aaronschlegel.me/principalcomponent-analysis-r-example.html.

[34] Cattell, R.B. (1966). The Scree test for the number of factors. Multivariate Behavioral Research, 1(2): 245-276. https://doi.org/10.1207/s15327906mbr0102_10 